\title{
Sensoriamento remoto aplicado ao mapeamento do uso do solo urbano e de assentamentos ilegais em Montes Claros-MG
}

\author{
Marcos Esdras Leite* \\ Jorge Luis Silva Brito ${ }^{* *}$
}

\section{Resumo}

O crescimento das cidades é um fenômeno global, sobretudo nos países em desenvolvimento. No contexto brasileiro, as cidades classificadas como intermediárias ou médias destacam-se como polo convergente de imigrantes, por apresentarem características importantes na atração populacional. Essa situação gera transformações significativas no sistema urbano, como, por exemplo, na forma de ocupação do solo. Esse cenário descreve a realidade da cidade de Montes Claros, uma vez que ela se destaca como polo de uma vasta região que abrange todo o Norte de Minas Gerais. Nesse sentido, o objetivo principal deste artigo foi mapear e analisar o uso do solo da cidade de Montes Claros, através do uso integrado do sensoriamento remoto com o SIG. O uso das geotecnologias, notadamente o sensoriamento remoto, com imagens de alta resolução espacial, e o Sistema de Informações Geográficas (SIG) permitiram extrair dados sobre a organização do uso do solo urbano de Montes Claros. Nesse momento foi possível quantificar e qualificar as classes predominantes nesse espaço. A construção de uma metodologia de mapeamento do espaço intraurbano foi imprescindível para criar uma legenda em níveis hierárquicos, permitindo mapear o uso do solo com vários focos, sendo que o interesse principal era identificar, na classe de baixa renda, as áreas

\footnotetext{
Professor do Departamento Geociências - UNIMONTES. (marcosesdras@ig.com.br).

** Professor do Instituto de Geografia - UFU (jbrito@ufu.br).
}

Geosul, Florianópolis, v. 26, n. 52, p 99-128, jul./dez. 2011 
LEITE, M.E. \& BRITO, J.L.S. Sensoriamento remoto aplicado ao ...

classificadas como favelas. Diante desses resultados, é importante o monitoramento constante, através das geotecnologias, do uso do solo urbano, uma vez que a ocupação ilegal desse solo é um problema recorrente nas cidades médias brasileiras.

Palavras-chave: Cidade; Sensoriamento Remoto; SIG; Montes Claros

Remote sensing applied to mapping the land use and urban settlements illegal in Montes Claros-MG

\section{Abstract}

The growth of cities is a global phenomenon, especially in developing countries. In the Brazilian context, cities are classified as intermediate sized or medium sized stand as convergent pole of immigrants, because they have important characteristics in the population attraction. This situation creates significant changes in the urban system, for example, in the form of land use. This scenario describes the reality of the city of Montes Claros, since it stands as a pole of a vast region that encompasses the whole North of Minas Gerais. In this sense, the main objective of this paper was to map and analyze land use in the city of Montes Claros, through the integrated use of remote sensing with GIS. The use of geo-technology, especially remote sensing, images with high spatial resolution, and the Geographic Information System - GIS allowed to extract data on the organization of urban land use in Montes Claros. At that moment it was possible to quantify and qualify the dominant classes in this space. The construction of a methodology of mapping intra-urban space was essential to create a legend in hierarchical levels, allowing the mapping the land use with multiple focuses, with the main aim to identify the class of low-income areas classified as slums. Given this analysis, constant monitoring is important, through geo-technology and the use of urban land, since the illegal occupation of that land is a recurrent problem in medium-sized cities in Brazil.

Key words: City; Remote Sensing; GIS; Montes Claros. 
LEITE, M.E. \& BRITO, J.L.S. Sensoriamento remoto aplicado ao ...

\section{Introdução}

O estudo sobre os diversos problemas urbanos está se expandindo em função da importância desse tema, uma vez que o processo de urbanização em escala global está em crescimento, impulsionado pelos países pobres. As cidades se tornaram o principal ponto de concentração de pessoas, isso foi constatado no relatório do UNFPA (2007), que apontou, através de estimativas, que a população rural foi superada pela população urbana no mundo. A diversidade econômica e a disponibilidade de serviços básicos e de infraestrutura são apontadas como fatores responsáveis por essa atração para a cidade.

Em função das diversas atividades e da alta densidade demográfica presentes na cidade, esse espaço apresenta complexidade na interpretação do uso do solo. E pensar em desenvolvimento das áreas urbanas exige compreender as diferentes funções e interações entre os componentes que produzem o espaço urbano. Nesse sentido, a identificação das funções de cada área da cidade é primordial para apresentar planos e propostas de desenvolvimento urbano que visem uma melhor qualidade de vida para os citadinos. Essa ideia é ratificada por Tenedório (1989) que afirma que as informações do uso do solo de determinado espaço são imprescindíveis para o planejamento territorial, pois são basilares para o processo de conhecimento da organização do espaço.

Analisar o uso do solo de uma cidade exige uma definição conceitual desse termo, haja vista que há divergência na concepção de alguns pesquisadores. A definição da Organização das Nações Unidas para a Agricultura e Alimentação (FAO, 1995) trata o uso do solo pelo critério funcional, assim, entende que o conceito de uso está relacionado à finalidade para a qual a terra é usada pela população local.

Henriques (2008) faz uma consideração importante sobre o fato de as abordagens sobre o uso do solo estarem relacionadas a um grande recorte espacial (apresentado em mapas de pequena 
LEITE, M.E. \& BRITO, J.L.S. Sensoriamento remoto aplicado ao ...

escala), pois está embutida nessa definição a "[...] idéia de solo como matéria-prima necessária ao sustento das pessoas e das suas actividades" (HENRIQUES, 2008, p. 107).

Corrobora com essa interpretação Cheng (2003), ao definir uso do solo, de maneira ampla, como o nível de acumulação espacial de atividades, tais como produção, transação, administração e residência com fortes relações de dinâmica entre elas. Dessa forma, esse autor define uso do solo urbano em uma perspectiva econômica, na qual o uso está relacionado às atividades econômicas e funcionais a que o solo se destina. Essa visão expõe o fato de o uso do solo ser um indicador da condição socioeconômica de uma cidade, imprimindo característica peculiar a cada área.

A transição de estado de uso do solo urbano indica mudança na dinâmica da cidade, ou seja, quando há uma redefinição funcional no padrão espacial pode-se concluir que houve influência de algum processo recente na cidade. A cidade média apresenta um percentual de crescimento urbano maior que outros tipos de cidade, assim essa mudança será mais intensa. Ainda que ocorra essa constante transformação nas cidades médias, há escassez de informações que mensurem e auxiliem na análise desse processo.

Essa deficiência de informações pode ser reduzida com a aplicação do sensoriamento remoto, através de imagens de alta resolução. De acordo com Novo (2008), a expressão alta resolução refere-se à imagem da superfície terrestre, captada por sensores orbitais, com resolução espacial menor que 5 metros. Entretanto, o avanço da tecnologia militar permitiu que imagem com resolução inferior a 1 metro fosse disponibilizada para uso civil.

O suporte das imagens de alta resolução foi decisivo para os estudos de uso do solo urbano, uma vez que, para mapear os alvos intraurbanos, é necessária uma escala que possibilite maior detalhamento, logo, há necessidade de uma base compatível com a escala pretendida. O sensoriamento remoto combinado ao SIG permite sistematização e análise dos padrões de uso de solo com alto índice de confiança. 
LEITE, M.E. \& BRITO, J.L.S. Sensoriamento remoto aplicado ao ...

Com o auxílio dessas tecnologias, este trabalho teve como objetivo principal mapear e analisar o uso do solo da cidade de Montes Claros. O mapa de uso de solo é definido por Tenedório (1989, p.10) como a "[...] representação temática, sobre base topográfica, dos tipos de utilização do solo de determinado território, num momento preciso." Por isso, esse produto cartográfico permite conhecer os vários tipos de uso do solo urbano, embora, devido à complexidade de funções no interior de uma cidade, esse mapeamento possa ser direcionado para uma determinada finalidade, ou seja, é possível fazer um mapeamento que prime pela identificação de classes específicas de uso de solo.

A cidade de Montes Claros localizada no Norte de Minas Gerais, como mostra a figura 1, é a mais dinâmica dessa mesorregião do estado. Essa cidade ocupa uma área de $101 \mathrm{~km}$, onde vive uma população de 289.183 habitantes, esse total corresponde a 94,22\% da população total do município (IBGE, 2000). Apresenta uma elevada população relativa, 2.979,44 hab. $/ \mathrm{km}^{2}$.

O crescimento urbano de Montes Claros ocorreu, de forma mais intensa, após a implantação do distrito industrial, entre 1960 e 1970. A configuração espacial de Montes Claros é reflexo da sobreposição de várias formas de ocupação do solo urbano e, como consequência, a cidade acumula problemas que não foram sanados pelo poder público ao longo dos anos, e com o tempo se agravaram. Visualizar a configuração da cidade de Montes Claros é possível, através da distinção dos determinados usos do solo urbano que permite de maneira cartográfica entender a forma de sua ocupação e, simultaneamente, denunciar as formas desiguais de consumo do solo urbano. 
LEITE, M.E. \& BRITO, J.L.S. Sensoriamento remoto aplicado ao ...

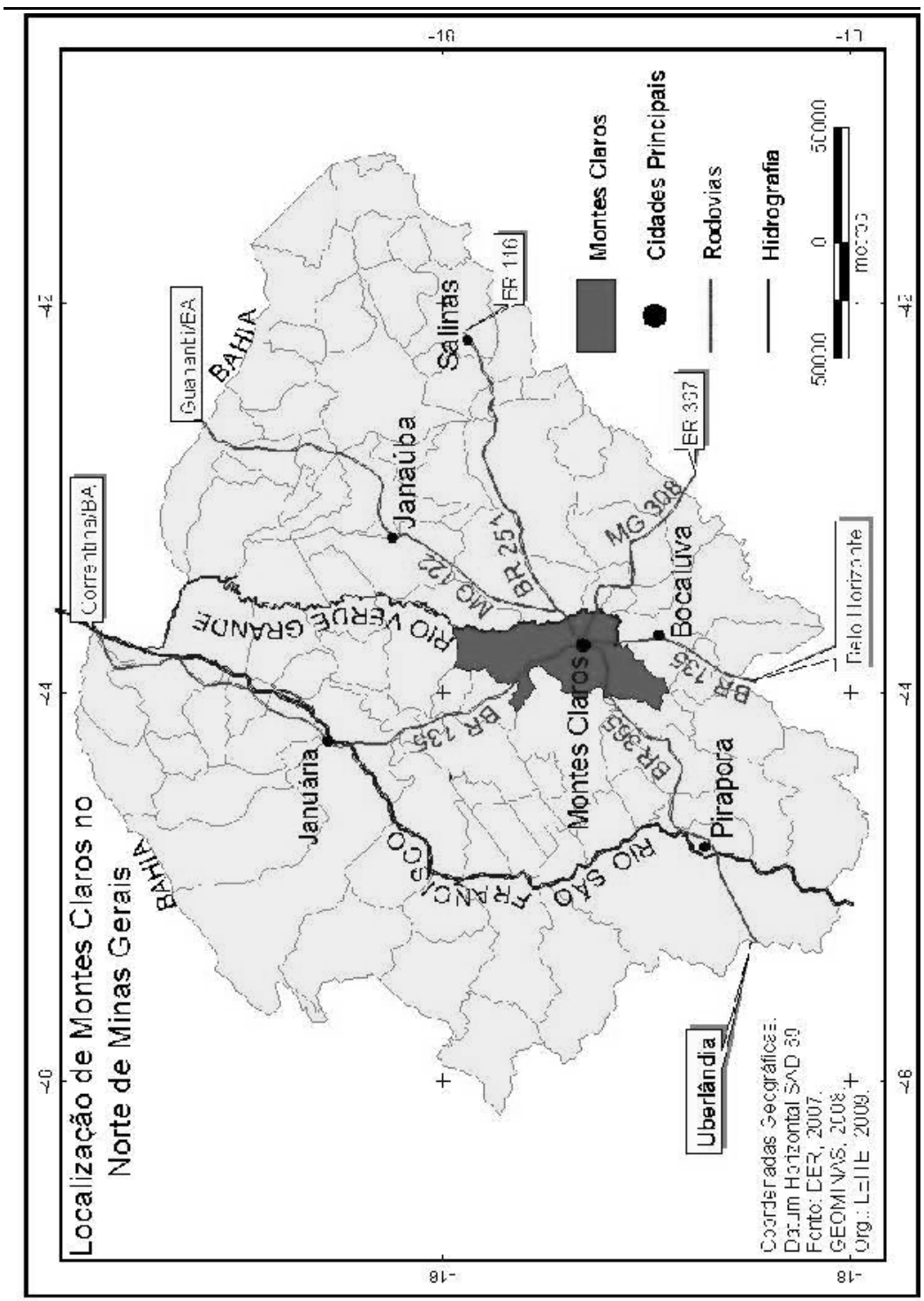

Figura 1: Localização do Município de Montes Claros no Norte de Minas Gerais. 
LEITE, M.E. \& BRITO, J.L.S. Sensoriamento remoto aplicado ao ...

\section{Procedimentos metodológicos}

Para atingir o objetivo proposto, foi definida uma legenda hierárquica ou de especificações sucessivas para o mapa de uso do solo urbano de Montes Claros, visando identificar as classes em níveis graduais. Para tornar a legenda coerente com o objetivo de mapear as ocupações informais, foi adotado um modelo de hierarquização que elimina as classes, que não são o foco deste estudo, no nível subsequente. $\mathrm{O}$ intuito dessa metodologia é alcançar o menor nível de detalhamento para ser analisado, no caso desta pesquisa foram os assentamentos urbanos informais, isto é, os loteamentos ilegais e as favelas.

Diante dessa meta há necessidade de classificar o uso do solo urbano baseando-se no detalhamento, a fim de se obter uma representação cartográfica qualitativa e quantitativa da ocupação da cidade. Diante disso, este trabalho apresentou uma classificação hierárquica do uso do solo urbano de Montes Claros/MG, tendo como base o sistema de classificação elaborado por Anderson, Hardy, Roach e Witmer, em 1976.

Essa proposta metodológica de mapeamento consistiu no ponto principal para se chegar aos objetivos propostos neste artigo, pois a primeira etapa para compreender o espaço urbano e as formas de ocupação ilegal do solo da cidade de Montes Claros foi mapear o uso do solo. Vale ressaltar que essa adaptação da metodologia de Anderson et al. (1976) foi desenvolvida com contribuições dos níveis do sistema europeu de mapeamento da terra, o CORINE Land Cover. A partir da integração dessas metodologias foi possível propor níveis de mapeamento que contemplassem os objetivos deste trabalho.

Esse mapeamento foi realizado com auxílio de dados de sensoriamento remoto, especificamente da imagem do satélite Quick Bird. Com isso, além da adaptação do sistema de Anderson et al. (1976), foram consideradas algumas contribuições do trabalho de Henriques (2008) com relação às unidades da classe residencial. Sempre atinando para o objetivo de mapear o uso do 
LEITE, M.E. \& BRITO, J.L.S. Sensoriamento remoto aplicado ao ...

solo, visando identificar e qualificar os assentamentos urbanos informais, foi definida uma classificação hierárquica, em que as classes de níveis iniciais que não estivessem ligadas à unidade mínima seriam excluídas no nível sucessor.

A figura 02 apresenta o sistema de classificação do uso do solo urbano da cidade de Montes Claros, o qual é composto por cinco níveis, sendo que o detalhamento por classes refere-se, apenas, aos níveis que interessam nesta pesquisa. Esta proposta levou em consideração as características da ocupação do solo na cidade estudada; para atender as especificações desse espaço foi realizada interpretação visual da imagem Quick Bird acompanhada de visita a campo para compreender as atualizações de uso. Além disso, foram adotadas como diretrizes para essa classificação: a possibilidade de aplicação em todos os recortes temporais analisados; a integração com dados de outras fontes; a compatibilidade com atualizações; e a utilização em diversas escalas de análises, considerando o nível de detalhamento.

Dessa forma, o trabalho se inicia pela área urbana, haja vista que é a classe menos detalhada nos sistemas de classificações analisados anteriormente. Isso acontece em decorrência da diversidade de usos no espaço urbano que necessita de uma escala muito grande para ser mapeado. No caso deste trabalho, considerou-se nesta etapa o perímetro urbano da cidade de Montes Claros que compreende uma área de $101 \mathrm{~km}^{2}$. A figura 2 traz a legenda hierárquica definida neste estudo, na qual há os cinco níveis de classificação de uso e ocupação do solo urbano.

A partir das etapas anteriores de classificação do uso e ocupação do espaço urbano de Montes Claros foi possível chegar ao nível IV do mapeamento, o qual classificou a parte residencial de baixa renda da cidade em área de ocupação formal e área de ocupação informal. Para identificar as áreas da cidade de Montes Claros que se enquadram numa situação de ocupação irregular foi necessário realizar pesquisa documental na Divisão de Urbanismo da Secretaria Municipal de Planejamento - SEPLA. 
LEITE, M.E. \& BRITO, J.L.S. Sensoriamento remoto aplicado ao ...

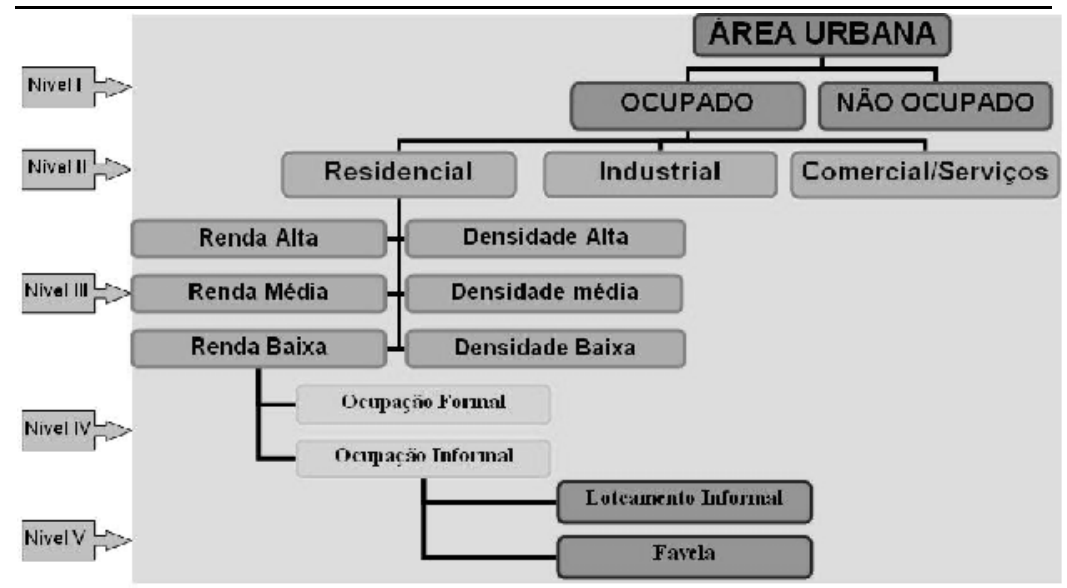

Figura 2: Legenda hierárquica com os cinco níveis de classificação de uso e ocupação do solo urbano de Montes Claros (Org.: Leite, M. E. 2008)

O trabalho de pesquisa documental consistiu em levantamento cartográfico na mapoteca da SEPLA, onde foram verificadas as plantas dos loteamentos da cidade. Através das plantas pode-se verificar a condição do loteamento em relação às exigências da Prefeitura Municipal, haja vista que nelas consta a aprovação ou a reprovação da SEPLA. Essas atividades descritas foram acompanhadas por funcionários da SEPLA que forneceram relevantes informações no decorrer desta etapa.

O mapeamento das áreas de ocupação irregular, previsto no nível $\mathrm{V}$ da metodologia desta pesquisa, diferenciou os loteamentos ilegais e as favelas. Os documentos e informações fornecidos pela SEPLA subsidiaram a identificação dessas áreas. Em contrapartida, para mapeamento dos loteamentos clandestinos foi preciso realizar visita a campo para constatar, através de depoimentos dos moradores, a situação da área habitada. Com isso, o processo de identificação dos assentamentos ilegais foi acompanhado por constantes visitas a campo e entrevista informal com os moradores. Para identificação das favelas foram usadas técnicas de interpretação 
LEITE, M.E. \& BRITO, J.L.S. Sensoriamento remoto aplicado ao ...

de imagens de satélites. Esse método foi útil para localizar área no perímetro urbano de Montes Claros que não apresentou regularidade no formato das ruas e falta de padrão nas quadras.

Dessa maneira, o critério principal neste trabalho para classificar um assentamento urbano como favela foi a forma de ocupação do solo urbano, isto é, se os moradores ocuparam um imóvel que não lhes pertencia. Esse é o ponto que distingue a favela das outras formas de moradia informal.

\section{Resultados}

\section{Mapeamento do uso do solo urbano}

$O$ resultado expresso na figura 3 mostra que, dos $101 \mathrm{~km}^{2} \mathrm{da}$ área urbana de Montes Claros, 59,8 km² estão ocupados, representando 59,3\% do perímetro urbano, enquanto $41,2 \mathrm{~km}^{2}$ não estão ocupados, o que corresponde a $41,7 \%$ da área urbana. Entretanto, vale destacar que a área não ocupada agrega terrenos que não são passíveis de ocupação humana, pois há impedimentos naturais e legais, como os lagos, os parques e as áreas de preservação permanente. Essa ressalva é importante, pois ao apresentar esses dados pode-se fazer uma inferência equivocada de que a área não ocupada representa o potencial de solo a ser ocupado ao longo dos anos.

Ao analisar o mapa de uso do solo, outra informação que pode ser absorvida trata da distribuição de espaços não ocupados. A área norte da cidade aparece com o maior percentual de área não ocupada, isso é uma consequência do baixo interesse imobiliário dessa região da cidade. $O$ poder público municipal usa esta área para implantar conjunto habitacional popular, e isso se torna um empecilho na atração populacional. Uma medida adotada pela Prefeitura Municipal para atrair maiores investimentos para a região norte da cidade foi a cessão de terrenos para implantação de instituições públicas. A doação do terreno para a construção do Instituto Técnico Federal - IFET é um indicativo dessa política. 
LEITE, M.E. \& BRITO, J.L.S. Sensoriamento remoto aplicado ao ...

Para maior detalhamento sobre os usos do espaço ocupado na área urbana de Montes Claros, o nível II, ilustrado, também, pela figura 3, traz informações sobre as categorias usadas nessa classificação, sendo essas: residencial, comércio/serviços e industrial.

A atividade industrial em Montes Claros sofreu, na década de 1990, uma crise motivada pelo fim dos incentivos da SUDENE e pela competição com novas áreas de atração industrial, tanto no Brasil quanto internacionalmente. Essa conjuntura provocou a saída de várias indústrias de Montes Claros. Apesar dessa crise que ocorreu na indústria montesclarense, a área destinada a essa atividade econômica se destaca no espaço urbano da cidade analisada, representando $6,75 \mathrm{~km}^{2}$ na área urbana. Isso devido ao fato de a localização das fábricas ter sido planejada e a sua concentração ter se direcionado para a região norte da cidade, onde se criou o distrito industrial. Além dessa área determinada para as indústrias, outros poucos espaços no interior da cidade são ocupados por esta atividade, conforme mostrado no mapeamento do uso do solo.

A classe de comércio e serviço tem, de acordo com a figura 3, o centro da cidade como polo irradiador que se expande para a periferia, através das principais vias de circulação da cidade. O uso da imagem de satélite associado à visita a campo permitiu verificar um processo de especialização comercial na área central, isto é, o centro da cidade está se tornando um ponto exclusivamente de comércio e serviços. Os imóveis que eram utilizados para uso de moradia foram adaptados e transformados em pontos comerciais. Outra tendência observada nessa parte da cidade é a verticalização, em que os imóveis antigos foram demolidos e, no lugar, foram construídos edifícios.

Além dessa inferência pode-se constatar a formação de subcentros comerciais e áreas de serviços especializados ao longo das vias de circulação. A formação de novas áreas de comércio e serviços provocou o surgimento de loteamentos e maior adensamento nos bairros existentes. 
LEITE, M.E. \& BRITO, J.L.S. Sensoriamento remoto aplicado ao ...

Setores de uso do solo urbano de Montes Claros: Nível II

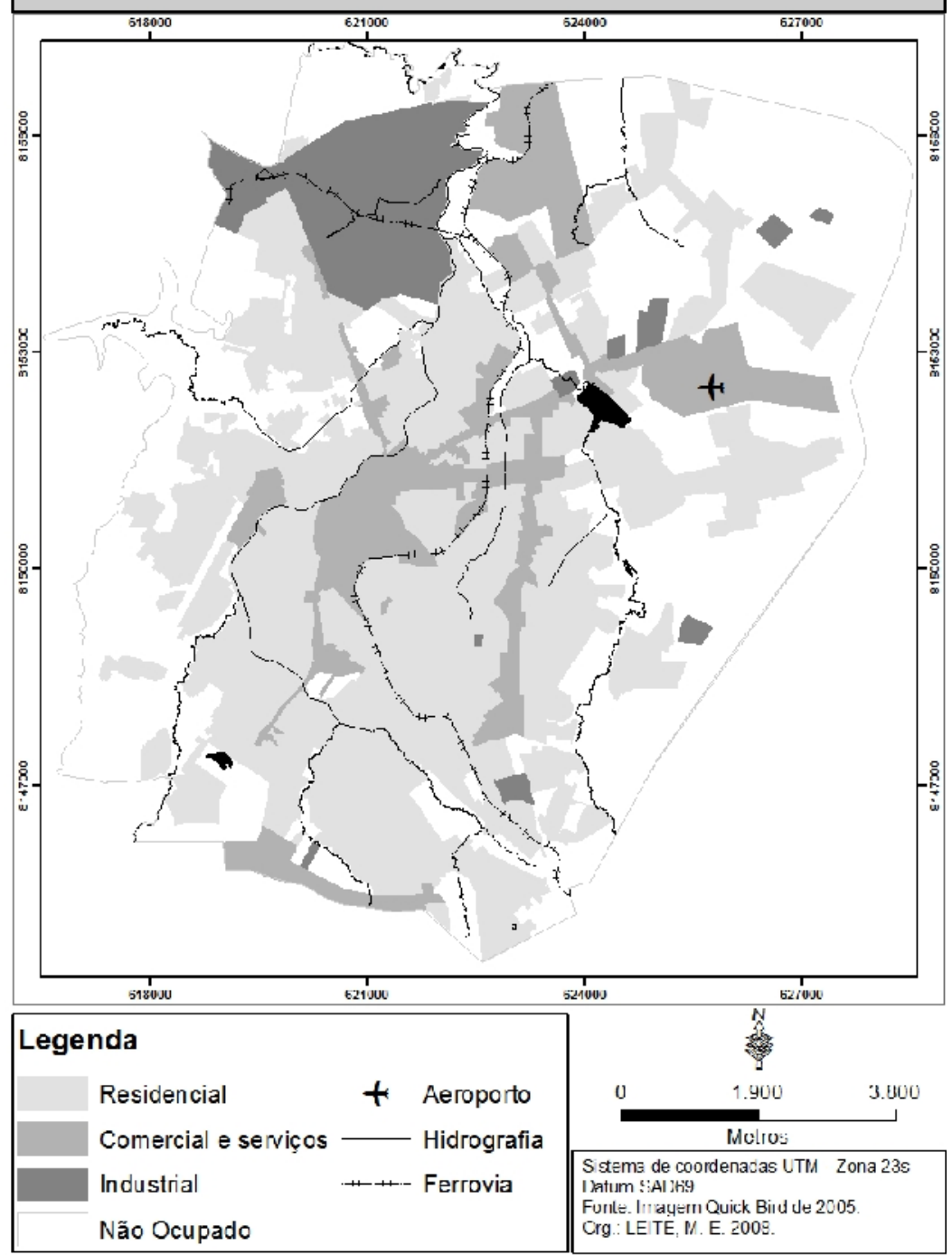

Figura 3: Setores de uso do solo urbano de Montes Claros-MG. 
LEITE, M.E. \& BRITO, J.L.S. Sensoriamento remoto aplicado ao ...

$\mathrm{Na}$ classe de comércio e serviços destaca-se, em termo de espaço ocupado, a atividade de transporte aéreo, em que está inserido o aeroporto. A área do aeroporto, que no início dos anos 1970 ficava isolada da parte adensada da cidade, atualmente, tem a área residencial se expandindo, sobretudo ao norte e ao sul do aeroporto. O outro setor de destaque na classe comercial e de serviços é o universitário. A concentração de instituições de ensino superior está relacionada com a presença das duas únicas universidades públicas, a Universidade Estadual de Montes Claros - Unimontes - na parte oeste da cidade e a Universidade Federal de Minas Gerais - UFMG - na área norte.

Há mudança, também, no uso do solo de residencial para comercial, com isso o uso de comércio e serviços ocupa a segunda maior área no espaço urbano de Montes Claros com $11,19 \mathrm{~km}^{2}$ no perímetro urbano. Além da mudança na função do solo urbano, a formação de novas áreas de comércio e serviços altera a classe social que ocupa esse espaço, pois, com a formação de novas centralidades, há aumento no valor do imóvel. Logo, a população de baixa renda é substituída pela classe de maior poder aquisitivo.

A classe residencial, apesar de ceder espaço para a atividade comercial, ocupa a maior parcela do espaço urbano, em dados absolutos 41,86 km², ou seja, quase metade de toda área do perímetro urbano. Com isso, se torna a principal categoria a ser analisada nesta pesquisa.

O uso residencial é uma classificação complexa que pode e deve ser explorada em outros níveis de classificação. Nessa perspectiva, a metodologia definida nesta pesquisa previu a identificação dos espaços residenciais e sua classificação de acordo com outros critérios, sendo eles: renda e adensamento. A análise desses outros níveis de classificações permitiu uma melhor compreensão das complexidades do uso residencial, bem como suas manifestações no espaço urbano de Montes Claros. 
LEITE, M.E. \& BRITO, J.L.S. Sensoriamento remoto aplicado ao ...

\section{Nível III: Setor residencial por classes de renda e de densidade}

A variável renda, apesar das críticas recorrentes, como erros de generalização e dificuldade de padronização espacial, é um dos principais indicadores para entender o espaço, uma vez que se configura como elemento importante para a análise social, bem como para o estudo da dinâmica econômica. Dessa forma, o planejamento de políticas públicas norteadas pelo princípio de justiça social deve perpassar a compreensão da distribuição da renda, isso para não incorrer no agravamento da desigualdade socioeconômica e, consequentemente, na promoção da segregação do espaço.

Conforme mostra a figura 4 , a distribuição das classes de renda apresenta-se setorizada. As áreas de alta renda estão concentradas no setor centro-oeste da cidade, essa localização é explicada pelo processo de expansão da cidade. A população de maior poder aquisitivo residia na parte oeste da área central, isso no período em que a maior parte ocupada estava no núcleo da cidade. Dessa forma, a ação direta do poder público, como agente imobiliário, financiando a infraestrutura dessa região promoveu a ocupação dessa população para o oeste da cidade. Essa situação elevou o valor do urbano nessa parte da cidade, o que implicou na formação de cluster de população de maior poder aquisitivo.

Observando a distribuição da população de classe média nota-se que sua concentração está na área pericentral, embora os novos loteamentos estejam direcionados para a parte sudoeste da cidade, próximos ao setor de alta renda. Nas outras regiões da cidade não se encontram loteamentos destinados à população com essa faixa de renda.

Depois de apresentar a área ocupada pela população de alta e média renda, verifica-se que predomina, no espaço urbano de Montes Claros, a população de baixa renda. A população de baixa renda ocupa uma área de $28,7 \mathrm{~km}^{2}$ na cidade, o que equivale a $68,5 \%$ do espaço de uso residencial. Esta é uma das justificativas para o trabalho ter, como foco principal de aplicação das geotecnologias, o espaço residencial da população de baixa renda. 
LEITE, M.E. \& BRITO, J.L.S. Sensoriamento remoto aplicado ao ...

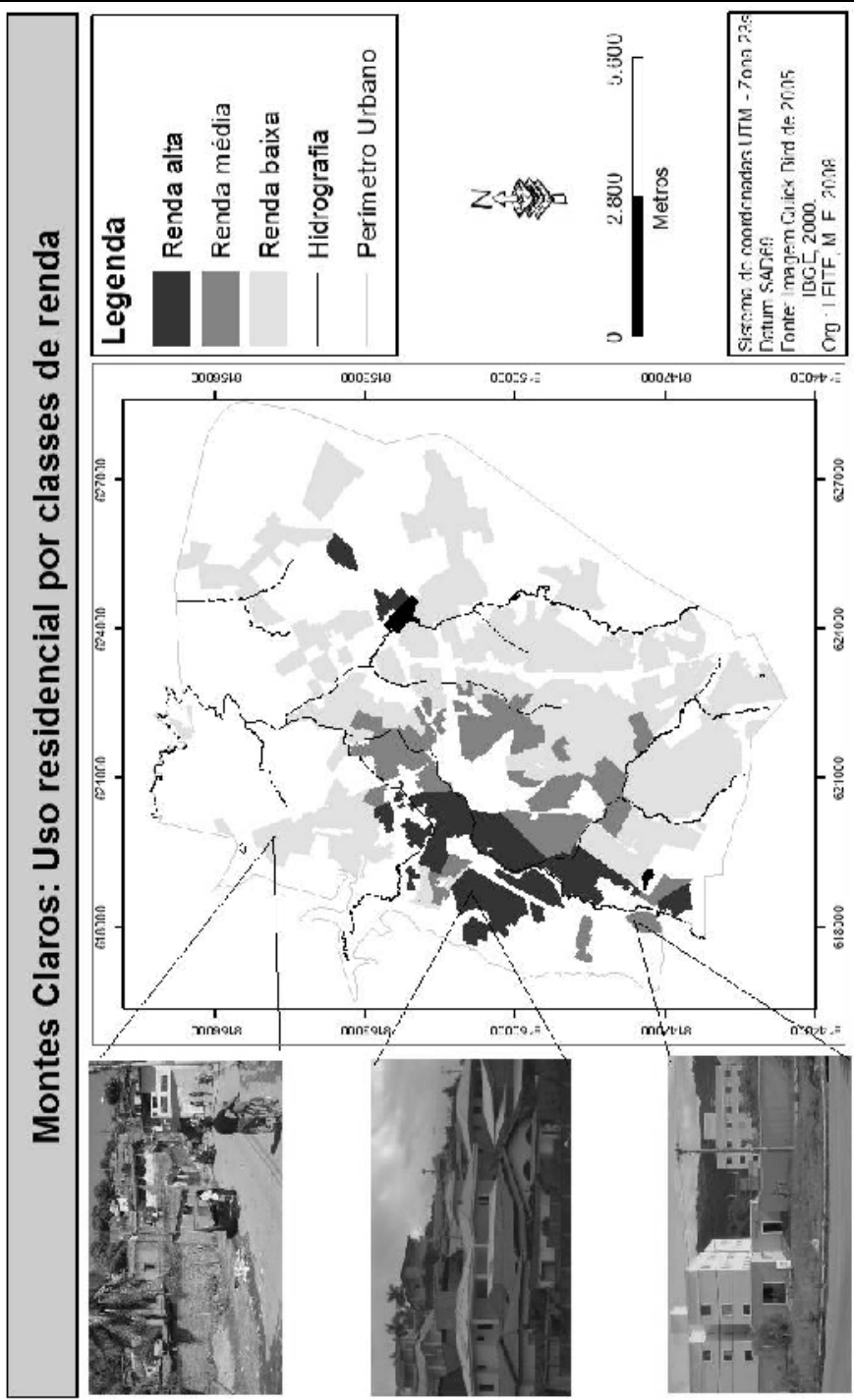

Figura 4: Uso residencial por classes de renda de Montes Claros/MG Nível III. 
LEITE, M.E. \& BRITO, J.L.S. Sensoriamento remoto aplicado ao ...

O padrão de distribuição da população de menor poder aquisitivo pela periferia se enquadra no modelo predominante nas cidades médias. Usando alguns estudos em cidades médias ${ }^{1}$ que mostram a distribuição da população por faixa de renda, encontrase uma semelhança na disposição espacial da população de renda baixa localizada na periferia sem infraestrutura.

Outra variável importante na classificação do solo urbano tratase da densidade de ocupação. A densidade refere-se ao número de imóveis edificados por unidade de área, o que implica no grau de utilização da infraestrutura (HENRIQUES, 2008). Por trazer essas informações, a densidade de ocupação é usada no zoneamento urbano. O zoneamento, para Souza (2006), é um instrumento de planejamento urbano por excelência. Embora, para Carvalho e Braga (2001, p.99), ele seja "o mais difundido instrumento urbanístico e, também, o mais criticado, tanto por sua eventual ineficácia, quanto por seus efeitos perversos (especulação imobiliária e segregação socioespacial)".

No zoneamento de uso e ocupação do solo urbano estabelecese uma ordem do uso da propriedade do solo e das edificações, isto é, são definidas zonas na cidade destinadas a funções específicas, além da sua densidade de ocupação. (CARVALHO; BRAGA, 2001). Como esse instrumento determina os usos na cidade e as zonas de adensamento prioritário, bem como as áreas de expansão da cidade, existem críticas sobre a maneira como são definidas essas zonas e a forma segregatória com que são impostas.

No caso da cidade de Montes Claros, na densidade das edificações, como representado na figura 5, predominam as zonas de alta densidade, com $22,7 \mathrm{~km}^{2}$ da área urbana, o que representa $54,2 \%$ do espaço residencial da cidade de Montes Claros. O setor residencial de média densidade de edificações está, em sua maior parte, localizado na área de transição do centro para a periferia e ocupa $11,6 \mathrm{~km}^{2}$ da cidade, equivalendo a $27,7 \%$ da classe de uso residencial. Enquanto

1 Foram usados como parâmetros os trabalhos sobre cidades médias publicados em Sposito (2001) e o trabalho de Amorim Filho e Sena Filho (2005). 
LEITE, M.E. \& BRITO, J.L.S. Sensoriamento remoto aplicado ao ...

que o setor identificado com baixa densidade está concentrado na periferia e representa $18 \%\left(7,6 \mathrm{~km}^{2}\right)$ do espaço residencial.

Outras informações importantes que se pode obter do mapa tratam dos locais de médio e baixo adensamento no interior das áreas consolidadas. Essas áreas foram ocupadas nos últimos vinte anos, pois até então eram mantidas vazias como reserva de mercado, isto é, eram usadas para a especulação imobiliária. Com a implantação de infraestrutura e de equipamentos urbanos houve uma significativa valorização do solo urbano, o que levou os proprietários dos terrenos a loteá-las.

Pode-se perceber na figura 5 e na tabela 1 que a densidade de ocupação residencial alta predomina em todas as faixas de renda e a renda baixa predomina em todos os níveis de densidade. Logo, prevalece, em Montes Claros, a área residencial de baixa renda e com densidade de edificações elevada.

Tabela 1: Renda e Densidade $\left(\mathrm{km}^{2}\right)$

\begin{tabular}{lc|c|c|c}
\hline & $\begin{array}{c}\text { Renda } \\
\text { Alta }\end{array}$ & $\begin{array}{c}\text { Renda } \\
\text { Média }\end{array}$ & $\begin{array}{c}\text { Renda } \\
\text { Baixa }\end{array}$ & Total \\
\cline { 2 - 5 } Densidade Alta & 2,3 & 4,8 & 15,6 & 22,7 \\
Densidade Média & 2,2 & 1,0 & 8,4 & 11,6 \\
Densidade Baixa & 1,6 & 1,3 & 4,7 & 7,6 \\
Total & $\mathbf{6 , 1}$ & $\mathbf{7 , 1}$ & $\mathbf{2 8 , 7}$ & $\mathbf{4 1 , 9}$ \\
\hline
\end{tabular}

Fonte: Imagem Quick Bird, 2005.

Analisando a figura 5, nota-se que a distribuição das classes de densidade por renda segue um padrão em todas as faixas de renda, isto é, independentemente da renda os setores de maior densidade estão próximos ao centro e se tornam rarefeitos em direção à periferia. Essa fragmentação do espaço urbano é evidente, também, quando se analisa a distribuição das classes sociais, haja vista que a população de maior renda está concentrada na parte oeste, enquanto a classe de menor renda ocupa predominantemente os setores leste, norte e sul. Da mesma forma, a população de classe média localiza-se em grande parte na região pericentral. 
LEITE, M.E. \& BRITO, J.L.S. Sensoriamento remoto aplicado ao ...

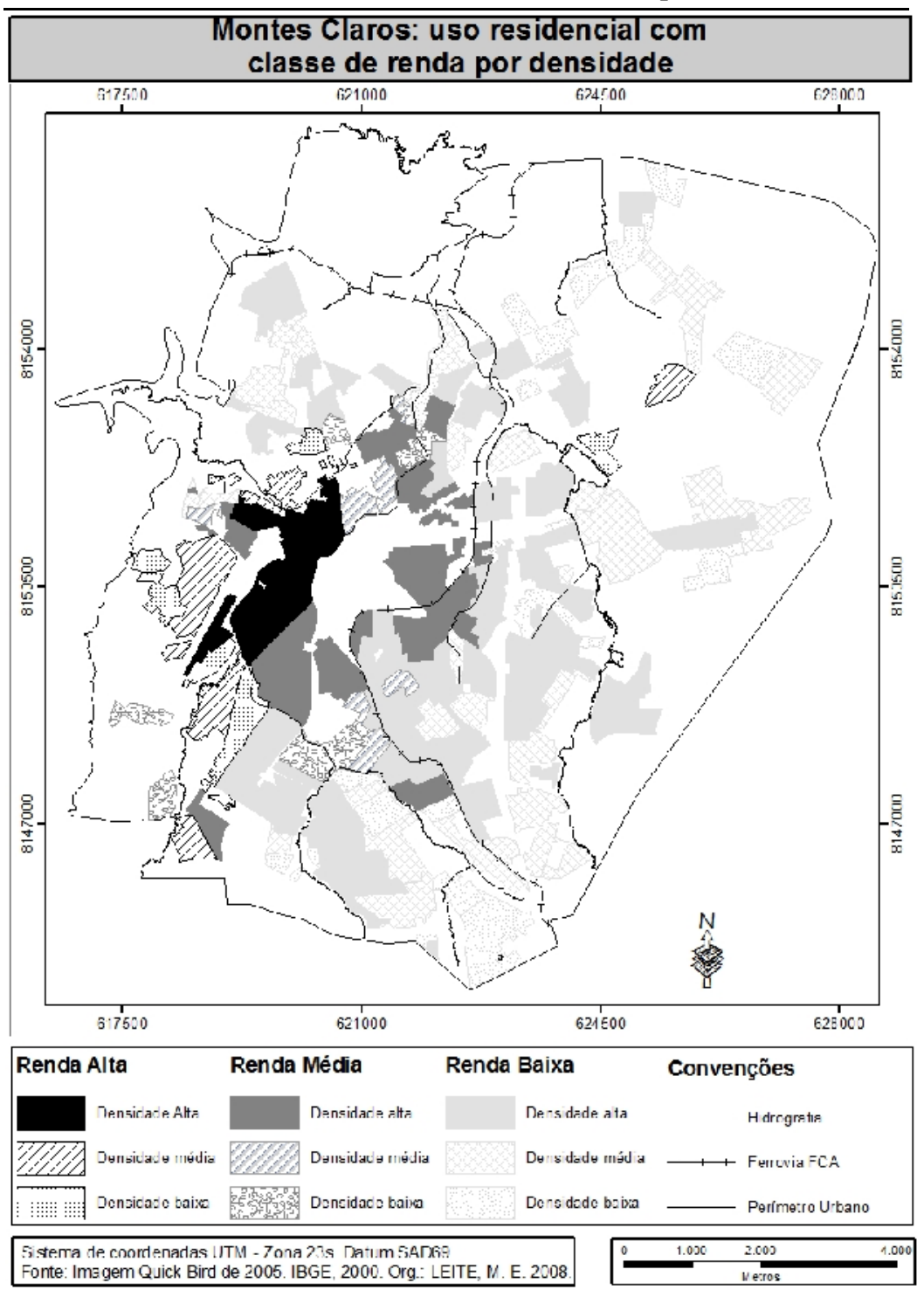

Figura 5: Montes Claros: uso residencial - classes de renda por densidade. 
LEITE, M.E. \& BRITO, J.L.S. Sensoriamento remoto aplicado ao ...

Com esta distribuição fragmentada das classes de uso do espaço intraurbano de Montes Claros, a análise da ocupação do solo por classes de renda e densidade é importante para apontar as áreas de baixa renda, sobretudo as que apresentam elevada densidade, como as ocupações ilegais.

\section{Mapeamento do espaço residencial de baixa renda legal e ilegal}

A discussão sobre a cidade legal e a cidade ilegal permeia os estudos sobre a urbanização brasileira desde seu primórdio, isso ocorre por haver uma relação intrínseca entre urbanização e exclusão. A cidade, como materialização das relações sociais, apresenta internamente espaços dicotômicos e essa desigualdade socioespacial é agravada pelo processo crescente de urbanização.

Na cidade média essa situação tem menor expressão que na cidade grande, visto que a primeira está num processo intenso de crescimento que culminará no mesmo estágio da segunda. Contudo, os problemas de habitação nas cidades intermediárias são preocupantes, principalmente, por estarem em expansão, o que tende a agravar o déficit de moradia, implicando na formação de novas aglomerações informais.

Para iniciar a análise do espaço residencial de baixa renda sob o paradigma da informalidade é imprescindível definir a legalidade e a ilegalidade das ocupações, bem como os critérios para essa classificação. Para Costa (2006 p.146), a parte legal da cidade, do ponto de vista da regularização urbanística, "[...] é aquela construída pelos agentes formalmente instituídos [...] e que traz consigo uma determinada ordem, em geral urbanística; é usualmente fruto de um projeto, pois essa é uma das exigências de tal ordenamento".

O loteamento é considerado regular ou legal quando, ainda como projeto proposto por um agente ou instituição formal, passa por algumas etapas de fiscalização e aprovação por parte do poder público municipal até a etapa final que consiste na implantação de 
LEITE, M.E. \& BRITO, J.L.S. Sensoriamento remoto aplicado ao ...

fato do empreendimento cumprindo todas as exigências legais. Por isso, o loteamento regular, de acordo com Costa (2006, p.148) possui uma "[...] urbanização completa, ou seja, onde todos os itens de consumo coletivo, de equipamentos e serviços encontramse presentes".

O descumprimento de alguma diretriz no processo de aprovação e implantação do loteamento torna-o irregular. E, quando há a implantação de um loteamento sem iniciar o processo de regularização, ou seja, sem o conhecimento do órgão responsável, é definido como clandestino.

Dessa forma, a existência de loteamentos irregulares nas cidades brasileiras é comum, haja vista que os entraves burocráticos e o custo para completar a regularização do loteamento, além da ineficácia da fiscalização incentivam os loteadores a desistir da regulamentação dos imóveis. No loteamento clandestino, o gasto de implantação é menor para tornar o preço de venda dos lotes mais atrativo e elevar o lucro do loteador, logo, apresentam características específicas, como a acentuada carência de infraestrutura e o desrespeito à legislação que ordena a ocupação do território.

Diferente dos loteamentos informais, o surgimento da favela não é uma ação mercadológica do solo urbano, isto é, não há um parcelamento do solo e a comercialização de lotes por um proprietário do terreno. A favela trata da ocupação de um terreno sem o consentimento do proprietário da terra, o que faz com que a demarcação dos lotes não obedeça a uma padronização de parcelamento, com isso, a disposição dos lotes é irregular e as vias de circulação são estreitas e sinuosas.

Maricato (2003) alerta para o fato de o loteamento ilegal e da favela serem as alternativas mais comuns de moradia da maior parte da população urbana de renda baixa. E acrescenta afirmando que, nas faixas de menor renda (menos de cinco salários mínimos), se concentra o déficit habitacional brasileiro.

No decorrer da etapa de mapeamento dos assentamentos informais foi identificado um problema recorrente nos loteamentos 
LEITE, M.E. \& BRITO, J.L.S. Sensoriamento remoto aplicado ao ...

irregulares, trata-se do não cumprimento do percentual de área reservada ao uso social e ambiental, isto é, a área destinada para a criação de áreas verdes e instalação de equipamentos públicos. A Lei 6.766/79 previa que a legislação municipal deveria estabelecer pelo menos $35 \%$ da gleba parcelada para uso social e ambiental, porém a Lei 9.785/99 transferiu para o município a distribuição desse percentual em área mínima para o sistema de circulação, a implantação de equipamentos urbanos e comunitários, a instalação de espaços livres e áreas verdes de uso público. Comumente, os municípios adotam de 15 a 20\% para sistema viário; 10 a 15\% para área verde e 5 a $10 \%$ para uso institucional.

Em Montes Claros, a Lei Municipal 3.720 de 09 de maio de 2007, que dispõe sobre o parcelamento do solo urbano, prevê que no mínimo sejam destinados, da área total do loteamento, 22,5\% ao sistema viário, 7,5\% para área verde e 5\% para área institucional. Essa Lei trouxe uma importante inovação, em relação às leis municipais anteriores de parcelamento do solo, uma vez que prevê que as áreas reservadas para uso institucional não poderão ser em terrenos que dificultem e onerem as edificações planejadas para aquela área. Embora exista essa norma, em alguns casos, não tem sido cumprida por falta de fiscalização.

Mesmo que esteja prevista a obrigatoriedade do percentual da área do loteamento para espaço verde e para uso institucional, alguns loteamentos de Montes Claros não seguiram essa diretriz. Esse problema foi predominante nos menores loteamentos, apesar da ocorrência em grandes loteamentos, como o Alterosa, na parte sul da cidade.

Outro entrave na regularização de loteamento na cidade analisada ocorre na etapa de registro em cartório do projeto de loteamento aprovado pelo município. As exigências previstas na legislação para concluir essa etapa tornam o custo do processo de registro do loteamento elevado, com isso os loteadores não registram o loteamento, assim este fica num estado de irregularidade. Vale destacar que a comercialização de imóveis 
LEITE, M.E. \& BRITO, J.L.S. Sensoriamento remoto aplicado ao ...

sem registro em cartório é considerada pela legislação brasileira como crime, logo, passível de multa ou reclusão.

Vale esclarecer que a implantação da infraestrutura mínima prevista na Lei Federal 9785/99 é de responsabilidade do loteador que tem o tempo máximo de quatro anos para a concretização das obras previstas no contrato. O valor dessa infraestrutura básica deve estar incluso no valor total do lote, podendo, através de negociação, o loteador repassar os recursos para a Prefeitura Municipal ou mesmo para os moradores implantarem a infraestrutura.

Ainda que haja essa exigência na legislação, existe o problema da ineficácia da fiscalização que permite que os lotes sejam pagos pelos moradores antes dos quatro anos exigidos para implantar a infraestrutura básica e, depois disso, o loteador não assume o compromisso contratual. Essa situação faz com que alguns loteamentos na cidade não apresentem estrutura de saneamento e energia elétrica; com o tempo essa obrigação é assumida pelo município. Por isso, em certas regiões da cidade há falta da infraestrutura mínima exigida em lei.

Esses problemas mencionados são os principais responsáveis por colocar os loteamentos em uma situação de irregularidade. No caso dos loteamentos clandestinos a ocorrência é pequena, pois, como se encontram totalmente ilegais, os loteamentos surgem rapidamente e na mesma velocidade os lotes são ocupados. Quanto às favelas, apesar de terem especificidades em relação ao loteamento clandestino, o processo de ocupação também é muito rápido.

Seguindo a metodologia de mapeamento do uso do solo urbano, foram definidas as etapas de trabalho para mapear as áreas de ocupação regular e irregular na cidade de Montes Claros. Como resultado foi gerado a figura 6 que traz uma classificação binária da área residencial de baixa renda, na qual estão identificadas as áreas de ocupação legal (regularizada) e ilegal (loteamento irregular, loteamento clandestino e favela).

Analisando a figura 6 percebe-se que, na área residencial de população de baixa renda, há um predomínio das ocupações 
LEITE, M.E. \& BRITO, J.L.S. Sensoriamento remoto aplicado ao ...

regulares, apesar de as moradias irregulares ocuparem uma porção significativa, aproximadamente $1 / 3$ desse espaço. A área residencial formal ocupa uma área de $19,1 \mathrm{~km}^{2}$, o que equivale a $18,9 \%$ do perímetro urbano, a 45,5\% da área residencial e a 66,6\% do espaço residencial de baixa renda, enquanto que a área de ocupação irregular corresponde a $9,6 \mathrm{~km}^{2}$, representando $9,5 \%$ do espaço da cidade, $22,9 \%$ da classe de uso de moradia e 33,4\% da área de menor renda.

Apesar da distribuição equilibrada dos espaços de ocupação informal, existe uma maior ocorrência na região norte da cidade. Esse fato pode ser explicado pela característica socioeconômica dos moradores que se concentram naquela região, com isso, os loteamentos implantados nesse setor atendem, principalmente, a população de baixa renda. Outro fato que pode ser considerado nessa análise é a baixa valorização do solo urbano nessa área, inibindo a construção de empreendimentos imobiliários.

Outra área de destaque de ocupação irregular é o extremo leste da cidade, na qual se encontram baixos indicadores sociais, como a renda per capita. Nessa área a ocupação se intensificou a partir da década de 1990, desde então a população de baixa renda tem se deslocado para essa área, em função da oferta de lotes irregulares de baixo valor. Como a disponibilidade de espaço para expansão desses loteamentos é maior, a oferta de lotes nessa área tende a crescer. Os dados desta pesquisa revelaram que os loteamentos de baixa renda que surgiram nos últimos cinco anos têm se concentrado nessa parte da cidade. Essa tendência na região leste da cidade provocou uma dicotomia social visível no espaço urbano de Montes Claros, haja vista que a região oeste é o ponto de atração da população de alta renda, enquanto que a região leste é responsável por receber a população de menor poder aquisitivo.

Diante dessas afirmações, o setor norte é o espaço de maior número de área de ocupação irregular, embora o maior crescimento nos últimos cinco anos tenha ocorrido na parte leste da cidade, devido à disponibilidade de área e às características dos loteamentos e aglomerados que se encontram implantados e adensados. 
LEITE, M.E. \& BRITO, J.L.S. Sensoriamento remoto aplicado ao ...

\section{Formas de ocupaçōes ilegais de baixa renda - Nível V}

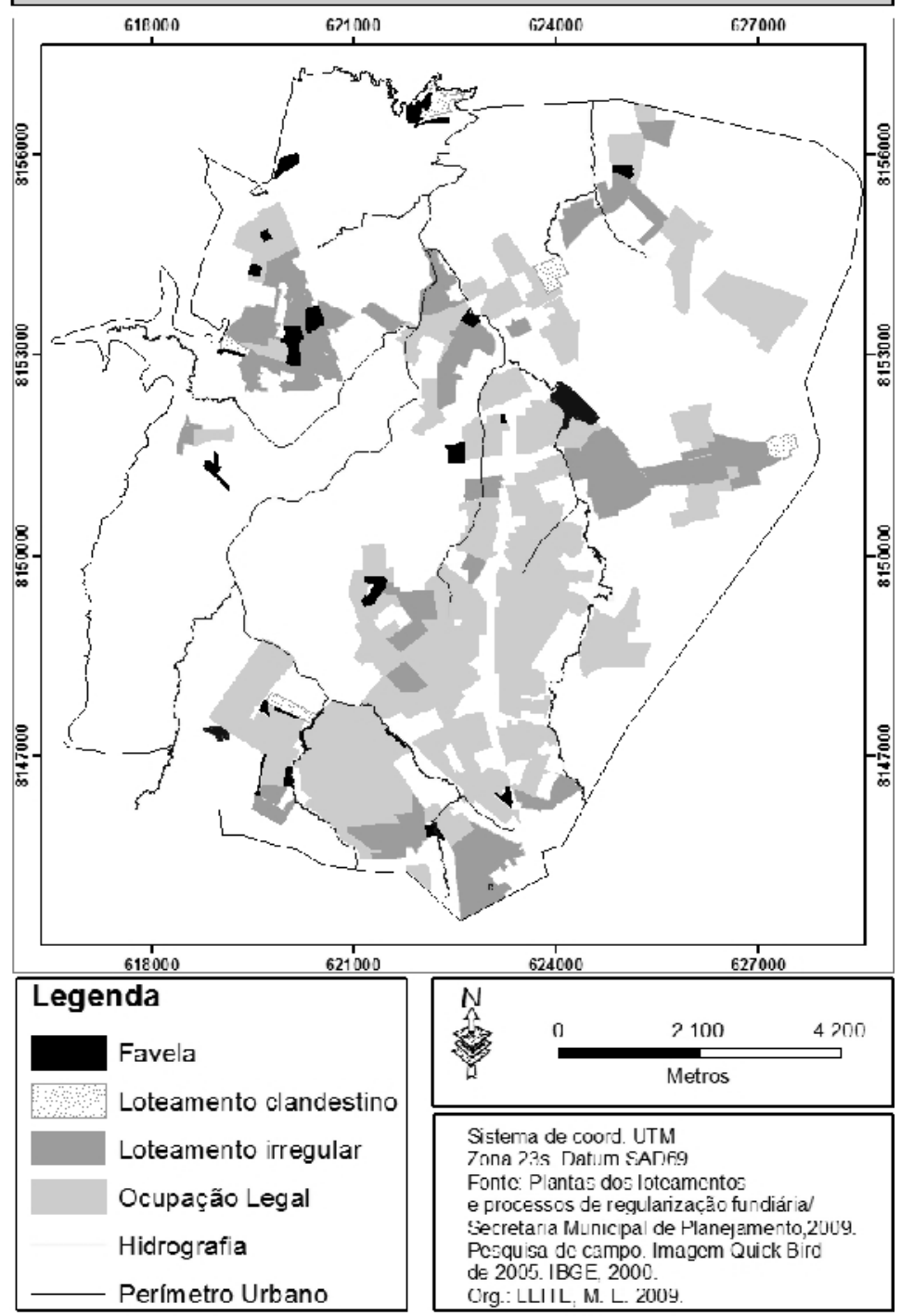

Figura 6: Formas de ocupações ilegais de baixa renda. 
LEITE, M.E. \& BRITO, J.L.S. Sensoriamento remoto aplicado ao ...

A distinção dos tipos de ocupações ilegais está exposta na figura 6 , que traz a distribuição delas pelo perímetro urbano da cidade estudada. Com isso, é possível afirmar que o loteamento irregular tem a maior representação nas ocupações informais de Montes Claros. Através da figura 6 percebe-se que há ocorrência de loteamento irregular em todos os setores de baixa renda da cidade, inclusive, na parte leste da cidade, está uma grande área contínua de loteamento irregular. Da mesma forma, ao norte destaca-se grande espaço de parcelamento irregular do solo urbano. Próximo à área central existem alguns loteamentos irregulares, no entanto esses são mais antigos que os localizados na extrema periferia da cidade.

A maior parte dos loteamentos irregulares está próxima a favela, isso indica que as formas de ilegalidade estão associadas. Existe um magnetismo socioeconômico que atrai pessoas de baixa renda para a proximidade de espaços de ocupação ilegal. Isso devido ao impacto da vizinhança no preço do solo urbano, logo, os terrenos perto de ocupações ilegais são mais baratos.

Essa relação provoca uma concentração de formas de ocupação ilegal do solo em determinados setores da cidade. Como resultado, a figura 6 mostra que as formas ilegais de moradia são limítrofes, isto é, a favela está na mesma parte da cidade que concentra os loteamentos irregulares e clandestinos. A ocorrência de loteamento clandestino é pequena, apenas cinco loteamentos, embora se destaquem por estarem concentrados na parte norte da cidade, sendo que há apenas um na zona sul.

A tabela 2 traz uma síntese estatística sobre as formas de ocupação ilegal e mostra que o loteamento irregular ocupa uma área de $8 \mathrm{~km}^{2}$, o que representa $83,3 \%$ do espaço de ocupação ilegal. Esse alto percentual está relacionado ao tamanho dos loteamentos que permanecem numa situação de irregularidade. Diferente desse último, a favela e o loteamento clandestino ocupam porções menores do espaço urbano, por isso, juntos, representam $16,7 \%$ da área de moradia informal, sendo que as favelas 
LEITE, M.E. \& BRITO, J.L.S. Sensoriamento remoto aplicado ao ...

correspondem a $0,94 \mathrm{~km}^{2}$ de área e os loteamentos clandestinos ocupam $0,66 \mathrm{~km}^{2}$.

Tabela 2:Dados sobre as formas de ocupação ilegal do solo urbano

\begin{tabular}{lc|c|c}
\hline \multicolumn{1}{c|}{ Ocupação Ilegal } & $\begin{array}{c}\text { Quantidade de } \\
\text { Unidades }\end{array}$ & Área absoluta & $\begin{array}{c}\text { Percentual de área } \\
\text { em relação ao } \\
\text { espaço ilegal }\end{array}$ \\
\hline Favela & 21 & $0,94 \mathrm{~km}^{2}$ & $9,8 \%$ \\
Loteamento Irregular & 29 & $8 \mathrm{~km}^{2}$ & $83,3 \%$ \\
Loteamento Clandestino & 5 & $0,66 \mathrm{~km}^{2}$ & $6,9 \%$ \\
\hline
\end{tabular}

Fonte: Imagem Quick Bird, 2005. PMMC, 2009. IBGE, 2000. Pesquisa de campo, 2009.

Para regularizar os loteamentos ilegais é preciso investir na melhoria da infraestrutura, além de criar instrumentos legais para a regularização jurídica da área. De acordo com Denaldi e Dias (2003), relatando a experiência na cidade de Santo André, a regularização jurídica passa pela criação do plano diretor, no qual estará prevista a criação das Zonas Especiais de Interesse Social ZEIS, que são espaços urbanos destinados à regularização fundiária de áreas de ocupação ilegal e à produção de habitações de interesse social. Para definição das ZEIS, estudos técnicos sobre a área afetada devem ser realizados, incluindo o levantamento cartográfico. Depois de criadas, as ZEIS devem ser aprovadas por decreto municipal e referendadas pelo conselho gestor criado para tomar as decisões sobre as ações nessas áreas. Como etapa final, a área de interesse deve ser averbada em cartório e o registro dos lotes ser realizado.

Uma alternativa para regularização fundiária dos loteamentos ilegais é a usucapião especial coletivo para fins de moradia; esse instrumento acelera o processo, pois os trâmites são mais simples que o processo apresentado anteriormente. Contudo, essa alternativa somente poderá ser usada em loteamento de ocupação mais antiga e que não esteja em área pública, pois neste caso a usucapião é inválida. Em ocupações ilegais em terrenos 
LEITE, M.E. \& BRITO, J.L.S. Sensoriamento remoto aplicado ao ...

públicos a recomendação, como escreveu Lins (2008), é a concessão para uso especial para fins de moradia que garante a segurança da posse e o direito à moradia. A concessão não assegura a propriedade, mas afirma o direito à posse e torna esse beneficio transmissível.

\section{Conclusão}

A cidade de Montes Claros passou por um processo de crescimento demográfico, em função do crescimento econômico, o que aumentou sua força centralizadora na rede urbana do Norte de Minas Gerais. Esta mesorregião do estado se caracteriza por apresentar municípios com baixos indicadores sociais e uma economia pouco desenvolvida. Esse cenário destoante entre a cidade de Montes Claros e os demais municípios do Norte de Minas Gerais fez com que a migração para a cidade de Montes Claros fosse intensa.

Essa transformação trouxe uma nova configuração social para a cidade. Há de se considerar que a maior parte da população imigrante era de baixa renda, com isso, boa parte do solo urbano foi ocupado por famílias de baixo poder aquisitivo. Mesmo que em menor quantidade, ocorreu a formação de setores de alta renda, assim como para a população de renda média.

A classe residencial é heterogênea e foi analisado em dois vieses, o de renda e o da densidade. Nesse último, o maior adensamento, naturalmente, concentra-se na área central e suas imediações, uma vez que são os espaços mais antigos da cidade e de maior valorização. No item renda, observou-se que a classe de alta renda está concentrada na parte centro-oeste da cidade. Da mesma forma, a classe média está concentrada na área pericentral e em alguns pontos da parte sudoeste do perímetro urbano. Contudo, a classe de maior destaque foi a de baixa renda que se apresenta em quase $70 \%$ do espaço destinado ao uso residencial. Isso mostra a influência da região no perfil da população de Montes Claros. Essa 
LEITE, M.E. \& BRITO, J.L.S. Sensoriamento remoto aplicado ao ...

afirmação se respalda no fato de a migração para essa cidade ser o principal fator do crescimento demográfico.

Esse cenário que se formou, com valorização do solo urbano, devido ao desequilíbrio entre oferta de terra e demanda, provocou a formação de espaços ilegais para fins de moradia. Nesse contexto, foram identificadas três formas de moradia ilegal na cidade: o loteamento irregular, o loteamento clandestino e a favela. A maior parte da área da "cidade ilegal" é ocupada por loteamento irregular. No entanto, foram identificadas vinte e uma favelas.

Essa constatação mostra que intervenção estatal é imprescindível para minimizar os efeitos perversos do crescimento das cidades médias. A redução dessa centralidade regional e diminuição do fluxo migratório é uma alternativa para o problema do crescimento demográfico elevado nesse tipo de cidade. A criação de programas eficazes de regularização urbanística e fundiária, bem como a maior fiscalização do uso do solo urbano são elementos importantes para melhorar a condição da moradia nas cidades médias.

Diante desse quadro, estudos de aplicação das geotecnologias no estudo urbano são importantes para gerar novos dados do espaço urbano, além de propor metodologias de uso das geotecnologias adequadas para a realidade local. Consequentemente, esses novos conhecimentos advindos da academia podem ser aproveitados na gestão urbana. Nessa perspectiva, este trabalho foi desenvolvido e os resultados encontrados revelaram novos conhecimentos sobre a cidade de Montes Claros, além de demonstrar que as geotecnologias têm um papel primordial na busca de novas informações sobre o espaço urbano. 
LEITE, M.E. \& BRITO, J.L.S. Sensoriamento remoto aplicado ao ...

\section{Referências bibliográficas}

ANDERSON, J.R. et al. A land use and land cover classification system for use with remote sensor data. Geological Survey Professional Paper 964. Washington, DC. 1976. 41p. Disponível em: http://landcover.usgs.gov/pdf/anderson.pdf. Acesso em: 13/04/2007.

CARVALHO, P.F. de; BRAGA, R. (Org.). Perspectivas de gestão ambiental em cidades médias. Rio Claro: LPM-UNESP, 2001.138p.

CHENG, J. Modelling spatial \& temporal urban growth. 203 p. Theses (Doctoral in Geographical Sciences) - Utrecht University. Utrecht, 2003.

Disponível em: http://www.itc.nl/library/Papers_2003/phd_theses/cheng _jianquan.pdf. Acesso em: 9/3/2008.

COSTA, H.S. de M. A "cidade ilegal": notas sobre o sensu comum e o significado atribuído à ilegalidade. In: BRANDÃO, A.L. (Org.). As cidades da cidade. Belo Horizonte: Editora UFMG, 2006. 197p. p.145-156

DENALDI, R.; DIAS, S.G. Limites da regularização fundiária: a experiência do município de Santo André. In: ABRAMO, P. (Org.). Cidade da informalidade: o desafio das cidades latinoamericanas. Rio de Janeiro: Livraria Sete Letras, FAPERJ, 2003. 327p. p.313-327.

EEA - EUROPEAN ENVIRONMENT AGENCY. Corine land cover. Copenhagen, 1990. 94p. Disponível em: http://www.eea.europa.eu/data-and-maps/data/corine-land-cover1990-clc1990-and-corine-land-cover-changes-1975-1990-in-a-10km-zone-around-the-coast-of-europe. Acesso em: 25/06/2007.

FAO. Food and Agriculture Organization of the United Nations. Planning for sustainable use of land resources. FAO land and water bulletin 2. Rome: FAO,1995. 67p. 
LEITE, M.E. \& BRITO, J.L.S. Sensoriamento remoto aplicado ao ...

HENRIQUES, C.D. MAPUTO, cinco décadas de mudança territorial: o uso do solo observado por tecnologias de informação geográfica. Lisboa: Cooperação Portuguesa, 2008. 238p.

LINS, R.D.B. A regularização fundiária como reconhecimento de direitos: os empreendimentos residenciais Vila Emater II e Vista Atlântica. In: VALENÇA, M. (Org.). Cidade (i)legal. Rio de Janeiro: Mauad X, 2008. 250p. p.219-241.

MARICATO, E. Conhecer para resolver a cidade ilegal. In: CASTRIOTA, L.B. Urbanização brasileira: redescobertas. Belo Horizonte: C/Arte, 2003. 304p. p.78-96.

NOVO, E.M.L. de M. Sensoriamento remoto: princípios e aplicações. 3. ed. São Paulo: Blucher, 2008. 363p.

SOUZA, M.L. de. Mudar a cidade: uma introdução crítica ao planejamento e à gestão urbanos. 4. ed. Rio de Janeiro: Bertrand Brasil, 2006. 556p.

TENEDÓRIO, J.A. Concepção de cartas de uso e evolução do solo por interpretação de fotografia aérea vertical. Almada: exemplo metodológico. Instituto Nacional de Investigação Científica. Centro de estudos de geografia e planejamento regional: FCSH-UNL, 1989. 80p.

UNFPA. Fundo de População das Nações Unidas. Situação da população mundial em 2007: Desencadeando o potencial para o crescimento urbano. Nova Iorque: 2007. 108p.

Recebido em maio de 2011

Aceito em abril de 2012 